Journal of Mathematics and Statistics 3 (4): 172-180, 2007

ISSN 1549-3644

(C) 2007 Science Publications

\title{
Numerical Treatment of the Mathematical Models for Water Pollution
}

\author{
F. B. AGUSTO and O. M. BAMIGBOLA \\ Department of Mathematical Sciences, Federal University of Technology Akure, Nigeria \\ Department of Mathematics, University of Ilorin, Nigeria
}

\begin{abstract}
To evaluate the environmental impact of pollution, mathematical models play a major role in predicting the pollution level in the regions under consideration. This paper examines the various mathematical models involving water pollutant. We also give the implicit central difference scheme in space, and a forward difference method in time for the evaluation of the generalized transport equation.
\end{abstract}

Key words: water pollution, dissolved oxygen, biological oxygen demand, contaminant transport

\section{INTRODUCTION}

"Pure water is the best of gifts that man to man can bring" -Spectator, July 30, 1920

Water, comprising over 70\\% of the earth's surface, is undoubtedly the most precious natural resource that exists on our planet. Without the seemingly invaluable compound comprised of hydrogen and oxygen, life on earth would be non-existent. It is essential for everything on our planet to grow and prosper David ${ }^{[9]}$.

It is easy to dispose of waste by dumping it into a river or lake. In large or small amounts, dumped intentionally or accidentally, it may be carried away by the current, but will never disappear. It will reappear downstream, sometimes in changed form, or just diluted. Freshwater bodies have a great ability to break down some waste materials, but not in the quantities discarded by today's society. This overload that results, called pollution, eventually puts the ecosystem out of balance $^{[24]}$.

Sometimes nature itself can produce these imbalances. In some cases, the natural composition of the water makes it unfit for certain uses: e.g., water flowing in the highly saline terrain of the prairies or gushing from highly mineralized springs in some parts of the country cannot sustain fish populations.

But most often our waterways are being polluted by municipal, agricultural and industrial wastes, including many toxic synthetic chemicals which cannot be broken down at all by natural processes. Even in tiny amounts, some of these substances can cause serious harm.

Many causes of pollution including sewage and fertilizers contain nutrients such as nitrates and phosphates. In excess levels, nutrients over stimulate the growth of aquatic plants and algae. Excessive growth of these types of organisms consequently clogs our waterways, use up dissolved oxygen as they decompose, and block light to deeper waters. This, in turn, proves very harmful to aquatic organisms as it affects the respiration ability of fish and other invertebrates that reside in water.

Pollution is also caused when silt and other suspended solids, such as soil, washoff plowed fields, construction and logging sites, urban areas, eroded river banks when it rains. Under natural conditions, lakes, rivers, and other water bodies undergo Eutrophication, an aging process that slowly fills in the water body with sediment and organic matter. When these sediments enter various bodies of water, fish respiration becomes impaired, plant productivity and water depth become reduced, and aquatic organisms and their environments become suffocated. Pollution in the form of organic material enters waterways in many different forms as sewage, leaves and grass clippings, or as runoff from livestock feedlots and pastures. When natural bacteria and protozoan in the water break down this organic material, they begin to use up the oxygen dissolved in the water. Many types of fish and bottom-dwelling animals cannot survive when levels of dissolved oxygen drop below two to five parts per million. When this occurs, it kills aquatic organisms in large numbers which leads to disruptions in the food chain.

Pathogens are another type of pollution that prove very harmful. They can cause many illnesses that range from typhoid and dysentery to minor respiratory and skin diseases. Pathogens include such organisms as bacteria, viruses, and protozoan. These pollutants enter

Corresponding Author: F.B. AGUSTO, Department of Mathematical Sciences, Federal University of Technology Akure, Nigeria 
waterways through untreated sewage, storm drains, septic tanks, runoff from farms, and particularly boats that dump sewage. Though microscopic, these pollutants have a tremendous effect evidenced by their ability to cause sicknesses.

Oxygen is required to support aquatic life and maintain water quality, it is the most important dissolved gas in water. Water in equilibrium with air at $25^{\circ} \mathrm{C}$ contains $8.3 \mathrm{mg} / \mathrm{L}$ of dissolved $\mathrm{O}_{2}$. Although water molecules contain an oxygen atom, this oxygen is not what is needed by aquatic organisms living in natural waters. A small amount of oxygen, up to ten molecules of oxygen per million of water, is actually dissolved in water. Fish and zooplankton breath dissolved oxygen, and without sufficient oxygen mortality will occur.

Dissolved Oxygen (DO) concentrations are affected by a number of factors. Higher DO is produced by turbulent actions such as waves, which mix air and water. Lower water temperatures also allows for retention of higher DO concentrations. Low DO levels tend to occur more often in warmer, slow moving waters. In general, low DO levels occur during the warmest summer months and particularly during low flow periods. Water depth is also a factor. In deep slow moving waters DO concentrations may be high near the surface due to wind action and plant photosynthesis, but may be entirely depleted (anoxic) at the bottom.

Oxygen consuming wastes include decomposing organic matter or chemicals that reduce DO in the water. Raw domestic wastewater contains high concentrations of oxygen consuming wastes that need to be removed before it can be discharged into a waterway. Maintaining a sufficient level of DO in water is critical to most forms of aquatic life.

Microorganisms such as bacteria are responsible for decomposing organic waste. When organic matter such as dead plants, leaves, grass clippings, manure, sewage, or even food waste is present in a water supply, the bacteria will begin the process of breaking down this waste. When this happens, much of the available dissolved oxygen is consumed by aerobic bacteria, robbing other aquatic organisms of the oxygen they need to live.

Biological oxygen demand (BOD) is an indicator for the concentration of biodegradable organic matter present in a sample of water. It can be used to infer the general quality of the water and its degree of pollution. BOD measures the rate of uptake of oxygen by microorganisms in the sample of water at a fixed temperature and over a given period of time.

Dissolved organic matter (DOM) is widely present in aquatic subsurface environments. It contains many biochemically identifiable classes of compounds such as sugars or amino acids, as well as fractions that are more coarsely classified, such as humics.

To evaluate the environmental impact of pollution, mathematical models play a major role in predicting the pollution level in the regions under consideration. ${ }^{[22,4,5 \text {, }}$ $13,17,18,23,1,10]$

In the subsurface, colloidal/bacterial particles are generated and/or mobilized by various mechanisms. The presence of colloids can affect the transport behavior of organic contaminants in soils and groundwater due to sorption on the surface of colloids/bacteria. ${ }^{[16,19,8]}$ In riverbank filtration, the mobile colloidal particles can increase the mobility of contaminants and change the degree of sorption and microbial degradation.

Several researchers have reported that organic compounds have strong affinity to DOM. Hassett and Andersion $^{[11]}$ have reported that hydrophobic organic compounds such as PCBs were bound to DOM in water. Carter and Suffet ${ }^{[6]}$ have examined the sorption of DDT to DOM. Chiou et al. ${ }^{[7]}$ have shown that the sorption of hydrophobic organic compounds onto DOM increased their aqueous solubility. Magee et al. ${ }^{[15]}$ have reported that hydrophobic compounds moved faster in the presence of DOM. In riverbank filtration, DOM can facilitate the contaminant transport as the mobile carrier. In addition, it can be utilized as a food source for bacteria.

In riverbank filtration, contaminant transport can be affected by the presence of bacteria. Lindqvist and Enfield $^{[14]}$ have reported that the transport of DDT and hexachlorobenzene could be facilitated in groundwater owing to their attachment on bacteria. Jenkins and Lion ${ }^{[12]}$ have demonstrated that highly mobile bacteria could increase the mobility of organic

contaminants such as PAHs. In addition, bacteria can reduce the contaminant concentration by microbial transformation.

Kim and Corapcioglu ${ }^{[21]}$ gave a model to simulate contaminant transport in riverbank filtration in the presence of DOM and bacteria. The model equations are solved numerically with a fully implicit finite difference method.

\section{CONTAMINANT TRANSPORT MODELS}

Describing contaminant transport requires the solution of the equation for saturated water transport and the convection-dispersion- reaction equation for contaminant transport through porous media. For the saturated zone of the subsurface, contaminant transport is assumed to be isothermal and a heat balance equation is not required. Microscopic contaminant transport 
model equations are developed using a small representative element of volume in the subsurface.

Water Transport: If only isothermal contaminant transport in the saturated zone of the subsurface is considered, the general physical law equation for saturated water transport through a representative small volumetric element in the porous structure of the subsurface is given as

$$
s_{t} \frac{\partial h}{\partial t}+W(x, t)=\nabla \bullet\left(K_{s a t} \bullet \nabla h\right)
$$

where $S_{t}$ is the storage coefficient of the aquifer, dimensionless, $h$ is hydraulic head, $c m, W(x, t)$ is the volume flux per unit area source term (positive for outflow and negative for inflow) $\mathrm{cm} / \mathrm{hr}, \nabla$ is the $\mathrm{del}$ operator defined as $\partial / \partial x \mathrm{~cm}^{-1}, \bullet$ denotes the dot product of vectors and tensors, $\mathrm{K}_{\mathrm{sat}}$ is the hydraulic conductivity tensor, related to fluid velocity, $V$, by Darcy's law, $\mathrm{cm} / \mathrm{hr}$.

Contaminant Transport: The general physicalchemical law, convective-dispersive-reaction contaminant transport equation for this same element of volume for a single chemical is given as

$$
\begin{aligned}
& \frac{\partial}{\partial t}\left(C+\frac{\rho_{B}}{\varepsilon}\right)=\nabla \bullet(D \bullet \nabla C)(x, t)-V \bullet \nabla C \\
& -\Lambda^{\omega} C^{\omega}-\frac{S_{S}}{\varepsilon} \frac{Q}{V_{o l}}
\end{aligned}
$$

where $S$ is contaminant concentration sorbed to soil or other solid surfaces, $\mathrm{g} / \mathrm{cm}^{3}, C$ is contaminant concentration, ${ }^{\mathrm{g} / \mathrm{cm} 3}, B$ is bulk density, $\mathrm{g} / \mathrm{cm}^{3}, \boldsymbol{\omega}$ is porosity, dimensionless, $D$ is the hydrodynamic dispersion tensor, $\mathrm{cm}^{2} / \mathrm{hr}, V$ is the fluid velocity vector in a porous media calculated from Darcy's law, $\mathrm{cm} / \mathrm{hr}$, $\Lambda$ is the reaction rate coefficient of order $\omega$ for transformation of the contaminant by either chemical or biological processes, $\left(\mathrm{cm}^{3} / \mathrm{g}\right) \omega^{-1} / \mathrm{hr}, \mathrm{Ss}$ is contaminant concentration in the source or sink fluid, $\mathrm{g} / \mathrm{cm} 3, Q$ is volumetric flow rate, $\mathrm{cm}^{3} / \mathrm{hr}, V_{o l}$ is the volume of the volumetric element used in developing this model, $\mathrm{cm}^{3}$.

For equilibrium sorption approximated by a linear Freundlich isotherm, the amount sorbed to solid components of the subsurface is approximated as

$$
\mathrm{S}=\mathrm{K}_{\mathrm{w}} \mathrm{C}
$$

where $K_{w}$ is the equilibrium sorption coefficient, $\mathrm{cm}^{3} / \mathrm{g}$. As used here, $K_{w}$ is an overall or composite equilibrium sorption coefficient and is a function of sorption to all solid components, e.g., silica, clay minerals, and organic matter. Substituting for $S$, and assuming that all biological and chemical transformations are first order reaction processes, gives

$$
R_{f} \frac{\partial C}{\partial t}=\nabla \bullet(D \bullet \nabla C)-V \bullet \nabla C-\Lambda-\frac{S_{S}}{\varepsilon} \frac{Q}{V_{o l}}
$$

where the retardation factor, $\mathrm{R}_{\mathrm{f}}$ (dimensionless), for equilibrium sorption is defined as

$R_{f}=1+\frac{\rho_{B} K_{\omega}}{\varepsilon}$

If sorption is not an equilbrium process, it can be described by an interphase mass transfer process as

$$
S=K C^{\omega}
$$

where $K$ is an overall mass transfer coefficient with units of $\mathrm{cm}^{3} / \mathrm{g}$ ) ${ }^{-1}$ and $\omega$ is the order of the mass transfer reaction of the chemical with the solid surfaces of the porous media. With this modification, the retardation factor is given as

$$
R_{f}=1+\left[\frac{\rho_{B} K_{\omega}}{\varepsilon} K C^{\omega-1}\right]
$$

Equation (2) is valid for a single chemical contaminant that is present in the aqueous phase in dilute concentrations. For most chemical contaminants, single chemical models are appropriate because the solubility of the chemical in the aqueous phase is very low. Thus, changes in time and space of contaminant concentrations are substantial. The first two terms on the right-hand side of Equation (2) are associated with the transport dynamics of flow in porous media, namely hydrodynamic dispersion and convective transport. The last term accounts for first-order chemical and biological reaction rate processes that transform or convert contaminants into other chemicals in the subsurface. For dilute solutions, the assumption that reaction rate processes can be represented as first-order processes is reasonable because only the concentration of the contaminant changes substantially during degradation or transformation. For example, with hydrolysis reactions the water concentration remains virtually unchanged, a pseudo first-order degradation mechanism. For the element of volume in the saturated zone of the subsurface, a general form of the concentration profile for contaminant transport in the subsurface is given as a function of these transport parameters and subsurface characteristics as

$C(x, y, z, t)=F\left(D, K_{s a t}, \nabla, K, \varepsilon, \rho_{B}\right)$

However, some subsurface contaminant transport problems occur in conduit-type flow aquifers that do not behave like flow-through porous media. For these 
aquifers and flow regimes, equivalent hydraulic characteristics must then be defined and used in Equation (7) to describe the contaminant concentration profile.

Bacteria Transport: Wastewater contain a great variety of pathogenic bacterias and viruses. In what follows, we consider a mixture of $N$ reacting species with partial densities $\mathrm{d}_{\mathrm{i}}, i=1, \cdots, N$ Let $d$ be the density of the mixture and $Y_{i}$ the mass fracture of species $i$. We have

$d=\sum_{i=1}^{N} d_{i}, \quad Y_{i=}=d_{i} / d, \quad i=1, \cdots, N$ If $v_{i} \operatorname{denot}$ es the velocity of species $i$, the macroscopic velocity is defined by

$v=\sum_{i=1}^{N} Y_{i} v_{i}$

The difference between $v$ and $v_{i}$ can be decomposed in the migration velocity and the diffusion velocity, the former representing, for instance, sedimentation:

$$
v-v_{i}=\sigma_{i}+v_{i} \text {. }
$$

According to Onsager's law (see Bermudez ${ }^{[3]}$ ), we can write

$d_{i} v_{i}=-\beta_{i} \nabla d_{i} \quad i=1, \cdots, N$

The mass conservation equation is:

$\frac{\partial d_{i}}{\partial t}+\nabla\left(d_{i} v\right)+\nabla\left(d_{i} \sigma_{i}\right)-\beta \Delta d_{i}=R_{i}+S_{i}$

where $\beta_{i}$ is the diffusivity term, while $R_{i}$ and $S_{i}$ represent the biochemical reaction term and the external sources respectively.

After discharge, concentration of bacterias or viruses decrease very quickly due to unfavorable conditions like lack of nutrients, low temperature, sun rays, etc. Death rate is frequently modeled as a first order reaction (see Bermudez ${ }^{[3]}$ ). This means that the $\mathrm{R}_{\mathrm{i}}$ term in equation (8) is given by

$$
R_{i}=-k_{i} C
$$

where $k_{i}$ is a kinetic constant.

Actually, biologists prefer to speak of the $T_{90, i}$, which is the time after which concentration decreases 90 percent. This parameter is related to $k_{i}$ by

$$
T_{90, i} \frac{\log 10}{k_{i}}
$$

On the other hand assuming pointwise wastewater discharges, as those from outfalls, the term $S_{i}$ in equation (8) is given by

$$
S_{i}=\sum q_{j} r_{i}^{j} \delta\left(P_{j}\right)
$$

equation (8) becomes

$\frac{\partial C}{\partial t}=-u \frac{\partial C}{\partial x}+D \frac{\partial^{2} C}{\partial x^{2}}-k_{i} C+\sum q_{j} r_{i}^{j} \delta\left(P_{j}\right)$

where $j$ is the number of the discharge, $q_{j}$ is the flow rate, $r^{j} i$ is the partial density of species $i$ for the $j^{\text {th }}$ discharge, $\delta\left(P_{j}\right)$ denotes the Dirac measure at the discharge point $P_{j}$

Biological Oxygen Demand BOD/ Dissolved Oxygen (DO): Oxygen plays a major role in all kinds of life. In particular, it is used by bacteria to decompose the organic matter. If the oxygen demand is not satisfied, plankton and other higher forms of animal life disappear. However, decomposition of organic matter goes on by anaerobic processes which do not use oxygen but produce sulfur of hydrogen and methane both having a nauseous smell. The organic matter can be measured in terms of the need of oxygen to decompose it, the so-called biological oxygen demand (BOD).If the pollution level is not too high this need can be satisfied by the dissolved oxygen (DO).

If the quantity of organic matter increases beyond a maximum value the dissolved oxygen is not enough to decompose it leading to modifications in the ecosystem. To avoid this phenomena some physico-chemical and/or biological treatments prior to discharge have to be made In what follows, we recall a classical model given by Streeter \& Phelps for the evolution of BOD and DO

$\frac{\partial \rho_{1}}{\partial t}+u \nabla \rho_{1}-\beta_{1} \Delta \rho_{1}=-k_{1} \rho_{1}+\frac{1}{h} \sum_{j=1}^{N} q_{j} r_{i}^{j} \delta\left(P_{j}\right)$

$\frac{\partial \rho_{2}}{\partial t}+u \nabla \rho_{2}-\beta_{2} \Delta \rho_{2}=-k_{1} \rho_{1}+\frac{1}{h} k_{2}\left(d_{s}-\rho_{2}\right)$

$-\frac{1}{h} r_{P} M+\frac{1}{h} \frac{I_{B}}{a+b I_{B}+c I_{B}^{2}} M+\frac{1}{h} F$ 
where $\rho_{1}$ is the concentration of the biochemical demand of oxygen (BOD), $\rho_{2}$ is the concentration of the dissolved oxygen (DO), $j$ is the number of the discharge, $\mathrm{q}_{\mathrm{j}}$ is the flow rate, $r_{i}^{j}$ is the partial density of species $i$ for the $j^{\text {th }}$ discharge, $\delta\left(P_{j}\right)$ denotes the Dirac measure at the discharge point $P_{j}, k_{l}$ is a kinetic parameter (function of temperature), $k_{2}$ is the interface transfer rate for oxygen, $\beta_{1}$ and $\beta_{2}$ are dispersion coefficients, $d_{s}$ is the saturation density of oxygen in water depending on temperature, $I_{B}$ is the intensity of sunlight on the bottom,

$M$ is the surface population density of algae, $r_{P}$ is a coefficient for respiration of algae, $F$ represents other external sources of oxygen.

\section{Dissolved Organic Matter (DOM)}

Bacteria Transport in Presence of DOM: The movement of bacteria in soils and groundwater is mainly controlled by the advectivell-dispersive transport. The mass balance equation for the aqueous-phase bacteria can be described as

$$
\begin{aligned}
& \frac{\partial\left(\theta C_{b}\right)}{\partial t}=-\frac{\partial}{\partial x}\left[-D_{b} \frac{\partial\left(\theta C_{b}\right)}{\partial x}+v_{w} \theta C_{b}\right] \\
& -K_{c} \theta C_{b}+k_{r} \rho_{b} \sigma_{b}+\mu\left(C_{c}+\frac{\rho_{s} K_{1} C_{c}}{\theta}\right. \\
& \left.+C_{d} \sigma_{c d}+C_{b} \sigma_{c b m}\right) \theta C_{b}-k_{d m} \theta C_{b}-k_{0} Y \theta C_{d}
\end{aligned}
$$

where $\theta$ is the water content $\left(n-\sigma_{b}\right), n$ is the porosity, $\sigma_{b}$ is the volumetric fraction of bacteria attached onto the solid matrix (volume of bacteria deposited per unit total volume of porous media), $C_{b}$ is the concentration of the aqueous-phase bacteria, $C_{d}$ is the concentration of DOM in the aqueous phase, $D_{b}$ is the hydrodynamic dispersion coefficient for bacteria $\left[L^{2} T^{l}\right], v_{w}$ is the porewater velocity $\left[L T^{l}\right], \sigma_{c d}$ is the mass fraction of the contaminant sorbed to DOM (mass of contaminant sorbed to DOM per unit mass of DOM), $\boldsymbol{\sigma}_{c b m}$ is the mass fraction of the contaminant sorbed to the mobile bacteria (mass of contaminant sorbed to mobile bacteria per unit mass of mobile bacteria), $\rho_{b}$ is the density of bacteria, $k_{c}$ and $k_{r}$ are the deposition and release rate coefficients of bacteria on the solid matrix $\left[T^{l}\right]$, respectively. $k_{d m}$ is the decay rate coefficient for the mobile bacteria $\left[T^{l}\right], k_{0}$ is the first-order decay rate coefficient for DOM $\left[T^{l}\right]$, and $Y$ is the yield factor (mass of bacteria formed per unit mass of food source utilized).
Contaminant Transport in Presence of DOM: The mass balance equation of the contaminant dissolved in the aqueous phase can be expressed as

$$
\begin{aligned}
& \frac{\partial\left(\theta C_{c}\right.}{\partial t}+\frac{\partial \rho_{s} \sigma_{c s}}{\partial t} \\
& =-\frac{\partial}{\partial x}\left[-D_{c} \frac{\partial\left(\theta C_{b}\right)}{\partial x}+v_{w} \theta C_{c}\right] \quad \text { where } C c \text { is } \\
& -k_{p} \theta C_{c}-k_{q} \theta C_{d} \sigma_{c d}+k_{3} \theta C_{c}-k_{4} \theta C_{b} \sigma_{c b m} \\
& -k_{c} \theta C_{b} \sigma_{c b m}-\frac{\mu C_{c}}{Y}\left(\theta C_{b}+\rho_{b} \sigma_{b}\right) \\
& -\frac{\mu \rho_{s} \sigma_{c s}}{Y \theta}\left(\theta C_{b}+\rho_{b} \sigma_{b}\right)
\end{aligned}
$$

the concentration of the contaminant dissolved in the aqueous phase, $\boldsymbol{\sigma}_{s}$ is the dry bulk density of the solid matrix, $\boldsymbol{\sigma}_{c s}$ is the mass fraction of the contaminant sorbed onto the solid matrix (mass of contaminant sorbed per unit solid mass of porous media). $D_{c}$ is the hydrodynamic dispersion coefficient of the contaminant dissolved in the aqueous phase $\left[L^{2} T^{l}\right], k_{-p}$ and $k_{q}$ are the adsorption and desorption rate coefficients for the contaminant on DOM $\left[T^{l}\right], \quad k_{3}$ and $k_{4}$ are adsorption and desorption rate coefficients of the contaminant on bacteria $\left[T^{l}\right]$,

respectively. $\mu=\mu_{\text {max }} / K_{s}, \mu_{\max }$ isthe maximum growth rate $\left[T^{I}\right]$, and $K_{s}$ is the half-constant $\left[M L^{-3}\right]$.

If the sorption relationship between the aqueous phase and the solid matrix is assumed to be an equilibriumcontrolled process and represented by a linear isotherm, the mass fraction of the contaminant sorbed onto the solid matrix can be presented as

$$
\sigma_{c s}=K_{1} C_{c}
$$

where $K_{l}$ is the equilibrium distribution coefficient of contaminant between the aqueous phase and the solid matrix $\left[L^{3} M^{-1}\right]$.

$$
\begin{aligned}
& \frac{\partial\left(R_{c} \theta C_{c}\right)}{\partial t}=\frac{\partial}{\partial x}\left[-D_{c} \frac{\partial\left(\theta C_{c}\right)}{\partial x}+v_{w} \theta C_{c}\right] \text { where } R_{c} \text { is } \\
& -k_{p} \theta C_{c}-k_{q} \theta C_{d} \sigma_{c d}-2 k_{3} \theta C_{c}-k_{4} \theta C_{b} \sigma_{c b m} \\
& -k_{c} \theta C_{b} \sigma_{c b m}-\frac{\mu R_{c}}{Y}\left(C_{b}+\frac{\rho_{b} \sigma_{b}}{\theta}\right) \theta C_{c}
\end{aligned}
$$

the contaminant retardation factor, and represented

as $R_{c}=1+\left(\rho_{s} k_{1}\right) / \theta$ 
The one dimensional transport equation for the contaminant sorbed to DOM is:

$$
\begin{aligned}
& \frac{\partial\left(\theta C_{d} \sigma_{c d}\right)}{\partial t}=-\frac{\partial}{\partial x}\left[-D_{d} \frac{\partial\left(\theta C_{d} \sigma_{c d}\right)}{\partial x}+v_{w} \theta C_{d} \sigma_{c d}\right] \\
& -k_{p} \theta C_{c}-k_{q} \theta C_{d} \sigma_{c d}-\frac{\mu C_{b}}{Y}\left(\theta C_{d} \sigma_{c d}\right)
\end{aligned}
$$

The one-dimensional transport equation for the contaminant sorbed to the mobile bacteria is:

$$
\begin{aligned}
& \frac{\partial\left(\theta C_{b} \sigma_{c b m}\right)}{\partial t}=-\frac{\partial}{\partial x}\left[-D_{b} \frac{\partial\left(\theta C_{b} \sigma_{c b m}\right)}{\partial x}+v_{w} \theta C_{b} \sigma_{c b m}\right] \\
& +k_{3} \theta C_{c}-k_{4} \theta C_{b} \sigma_{c b m}-k_{c} \theta C_{b} \sigma_{c b m}-\frac{\mu C_{b}}{Y}\left(\theta C_{b} \sigma_{c b m}\right)
\end{aligned}
$$

\section{NUMERICAL SOLUTION}

\section{2-Dimensional Transport Equation}

The 2-D transport equation can be generalized as

$$
\begin{aligned}
& \frac{\partial}{\partial t} C(x, y, t)=-\frac{\partial(u C(x, y, t))}{\partial x}+D \frac{\partial^{2}}{\partial x^{2}} C(x, y, t) \\
& -\frac{\partial(v C(x, y, t))}{\partial y}+D \frac{\partial^{2}}{\partial y^{2}} C(x, y, t)+R(C)+S(C)
\end{aligned}
$$

where $C$ is concentration of solute (bacteria or contaminant), $u$ and $v$ are the fluid velocity (which may be obtained from either the Navier-Stokes equation or the shallow water equation ), $D$ is the diffusivity term, while $R$ and $S$ represent the biochemical reaction term and the external sources respectively.

The boundary and initial conditions needed to solve equation (11) are:

$C(x, y, 0)=C_{0} \quad$ and $\left.\quad \frac{\partial C}{\partial x}\right|_{x-0, L}=0,\left.\frac{\partial C}{\partial y}\right|_{y=0, L}=0$

The mass transport equation (11) can be solved by using the classical Crank-Nicolson finite difference scheme which is an implicit central difference scheme in space, and a forward difference method in time. The stability of the methods is controlled by the dispersion and advection Currant number,

defined as

$$
C_{a d v}=\frac{v \Delta t}{\Delta L} \quad \text { and } \quad C_{\text {disp }}=\frac{D \Delta t}{\Delta L^{2}}
$$

The finite difference representation (see Andrea Bagnera) of equation (11) is for any point $i, j$, (a generic point $(x, y)$ on the grid) at any time $t)$ is :

$$
\begin{gathered}
\frac{C_{i, j}^{+1}-C_{i, j}}{\Delta t}+u_{i, j}^{t+1} \frac{C_{i+1, j}^{+1}-C_{i-1, j}^{+1}}{2 \Delta x}+v_{i, j}^{t+1} \frac{C_{i, j+1}^{+1}-C_{i, j-1}^{+1}}{2 \Delta y} \\
=D \frac{C_{i+1, j}^{+1}-2 C_{i, j}^{+1}+C_{i-1, j}^{+1}}{\Delta x^{2}}+D \frac{C_{i, j+1}^{+1}-2 C_{i, j}^{+1}+C_{i, j-1}^{+1}}{\Delta y^{2}} \\
R(C)_{i, j}^{t+1}+S(C)_{i, j}^{t+1}
\end{gathered}
$$

\section{1-Dimensional Transport Equation}

The 1-D transport equation can be generalized as

$$
\begin{array}{ll}
\frac{\partial}{\partial t} C(x, t)+q \frac{\partial}{\partial x} C(x, t)+D \frac{\partial^{2}}{\partial x^{2}} C(x, t)+k C(x, t)=0 & \text { in } Q \\
C(x, 0) & \text { in } \Omega \\
\frac{\partial}{\partial n} C(x, t) & \text { in } \Sigma
\end{array}
$$

where $R(C)$ in (11) is $-k C(x, t)$ and assuming there are no source term, i.e $S(C)=0$. If the velocity $u(x, t)$ is taken as a constant i.e. $q$, thus we have (12)

The mass transport equation (12) can be solved by using the Crank-Nicolson finite difference scheme. The finite difference representation of equation (12) is for any point $i$, (a generic point $(x)$ on the grid) at any time $t$ ) is :

$$
\begin{gathered}
\frac{C_{i}^{j+1}-C_{i}^{j}}{\Delta t}+\frac{q}{2}\left\{\frac{C_{i+1}^{j+1}-C_{i-1}^{j+1}}{2 \Delta x}+\frac{C_{i}^{j+1}-C_{i}^{j}}{2 \Delta x}\right\} \\
=-\frac{D}{2}\left\{\frac{C_{i+1}^{j+1}-2 C_{i}^{j+1}+C_{i-1}^{j+1}}{\Delta x^{2}}+\frac{C_{i+1}^{j}-2 C_{j}^{j}+C_{i-1}^{j}}{\Delta x^{2}}\right\} \\
+k(C)_{i}^{j+1}=0
\end{gathered}
$$

Thus we have

$$
\begin{aligned}
& -\gamma C_{i-1}^{j+1}+(2-\delta+2 \gamma+2 k) C_{i}^{j+1}+(\delta-\gamma) C_{i+1}^{j+1} \\
& =\gamma C_{i-1}^{j+1}+(2+\delta-2 \gamma) C_{i}^{j}+(\gamma-\delta) C_{i+1}^{j}
\end{aligned}
$$

where

$$
\delta=\frac{q \Delta t}{2 \Delta x}, \quad \gamma=\frac{D \Delta t}{\Delta x^{2}}
$$

The boundary and initial conditions needed to solve equation (3.2) are:

$C(x, 0)=C_{0} \quad$ and $\quad \frac{\partial C}{\partial x}=g(t)$

The boundary conditions (see Schilling and Harris (2000)) ) lcan be stated in general as:

$\left(1-u_{1}\right) C(0, t)-u_{l} C_{x}(0, t)=g_{1}(t)$ 
$\left(1-u_{2}\right) C(a, t)+u_{2} C_{x}(a, t)=g_{2}(t)$

If $u_{l}=0$ we have the Dirichlet boundary condition on the lower boundary of the domain $\Omega$ which we have taken to be regular in order to be able to apply the finite difference method of numerical approach to the solution. Otherwise we would need to propose another numerical method that will handle the nature of the domain, such as the finite element method. If on the other hand we have $u_{2}=0$ we have the Neumann boundary condition on the upper boundary of the domain.

In order to evaluate (14) at $i=1$ and $i=n$, the boundary values $C_{0}^{j}$ and $C_{n+1\}}^{j}$ are needed. To develop expressions for these values, we can use a two-point forward difference for the derivative in (15a) and a two-point backward difference for the derivative in (15b). This converts the boundary condition constraints into the following difference equations.

$$
\begin{aligned}
& \left(1-u_{1}\right) C_{0}^{j}-u_{1}\left(\frac{C_{1}^{j}-C_{0}^{j}}{\Delta x}\right)=g_{1}\left(t_{j}\right) \\
& \left(1-u_{2}\right) C_{n+1}{ }^{j}+u_{2}\left(\frac{C_{n+1}{ }^{j}-C_{n}^{j}}{\Delta x}\right)=g_{2}\left(t_{j}\right)
\end{aligned}
$$

Solving (3.6) for the boundary values yields

$$
\begin{aligned}
& \mathrm{C}_{0}{ }^{\mathrm{j}}=\frac{\mathrm{g}_{1}\left(\mathrm{t}_{\mathrm{j}}\right) \Delta \mathrm{x}+\mathrm{u}_{1} \mathrm{C}_{1}{ }^{\mathrm{j}}}{\mathrm{u}_{1}+\left(1-\mathrm{u}_{1}\right) \Delta \mathrm{x}} \\
& \mathrm{C}_{\mathrm{n}+1}{ }^{j}=\frac{\mathrm{g}_{2}\left(\mathrm{t}_{\mathrm{j}}\right) \Delta \mathrm{x}+\mathrm{u}_{2} \mathrm{C}_{\mathrm{n}}{ }^{j}}{\mathrm{u}_{2}+\left(1-\mathrm{u}_{2}\right) \Delta \mathrm{x}}
\end{aligned}
$$

The Crank-Nicolson equations can be expressed in vector form be letting $\mathrm{C}^{\mathrm{j}}=\left[\mathrm{C}_{1}, \mathrm{C}_{2}^{\mathrm{j}}, \cdots, \mathrm{C}_{\mathrm{n}}^{\mathrm{j}}\right]^{\mathrm{T}}$ denote the solution at time $t_{k}$ for $0 \leq \mathrm{j} \leq \mathrm{m}$. Suppose both boundary conditions are Neumann, which means $u_{1}=1, u_{2}=1$ in (3.5). For the case $n=5$, this result in the following implicit linear algebraic systems. suppose

$$
\begin{aligned}
& \mathrm{A}=(2-\delta+2 \gamma+2 \mathrm{k}), \quad \mathrm{B}=(\delta-\gamma), \\
& \mathrm{C}=(2+\delta-2 \gamma), \quad \mathrm{D}=(\gamma-\delta)
\end{aligned}
$$

$$
\left[\begin{array}{ccccc}
A & B & 0 & 0 & 0 \\
-\gamma & A & B & 0 & 0 \\
0 & -\gamma & A & B & 0 \\
0 & 0 & -\gamma & A & B \\
0 & 0 & 0 & -\gamma & A
\end{array}\right] C^{j+1}
$$$$
=\left[\begin{array}{lllll}
C & D & 0 & 0 & 0 \\
\gamma & C & D & 0 & 0 \\
0 & \gamma & C & D & 0 \\
0 & 0 & \gamma & C & 0 \\
0 & 0 & 0 & \gamma & C
\end{array}\right] C^{j}
$$$$
+\left[\begin{array}{c}
\gamma\left(C_{0}^{j+1}+C_{0}^{j}\right) \\
0 \\
0 \\
0 \\
(\delta-\gamma)\left(C_{n+1}^{j+1}+C_{n+1}^{j}\right)
\end{array}\right]
$$

The stability of the methods is controlled by the dispersion and advection Currant number, defined as

$$
\begin{gathered}
\mathrm{C}_{\mathrm{adv}}=\frac{\mathrm{v} \Delta \mathrm{t}}{\Delta \mathrm{x}} \text { and } \mathrm{C}_{\text {disp }}=\frac{\mathrm{D} \Delta \mathrm{t}}{\Delta \mathrm{x}^{2}} . \\
\text { RESULTS AND DISCUSSION }
\end{gathered}
$$

We solve the contaminant transport model by implementing the Crank-Nicolson numerical scheme, while varying the different parameter values. We observe in general, a decrease in contaminant concentration. In fig 1 , the profile for varying the decay rate, we observe that with a higher decay rate, the concentration of contaminant decreases faster than with a lower decay rate. In fig 2 , the profile for varying contaminant velocity, we observe that the contaminant concentration with a higher velocity decreases at a higher rate than that with a lower velocity. In fig 3, the profile for varying the diffusive term, we saw that when the rate of diffusion is high, the concentration of contaminant decreases faster. 


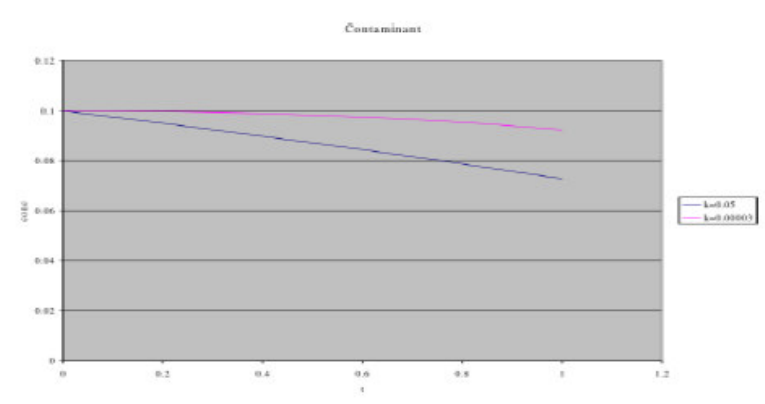

Fig 1: Varying the value for the rate of decay ' $\mathrm{k}$ '

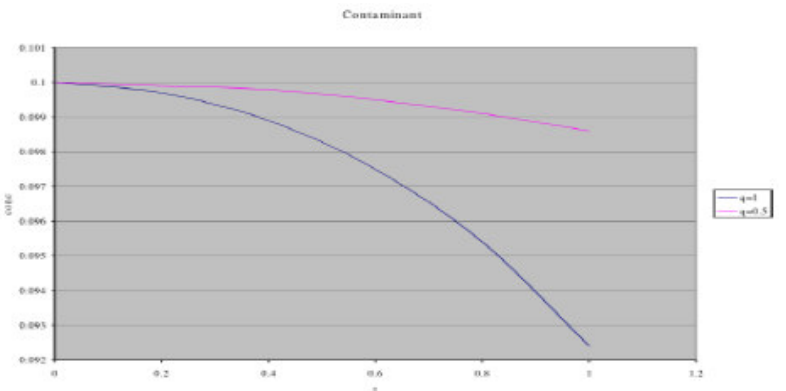

Fig. 2: Varying the value for the velocity term 'q

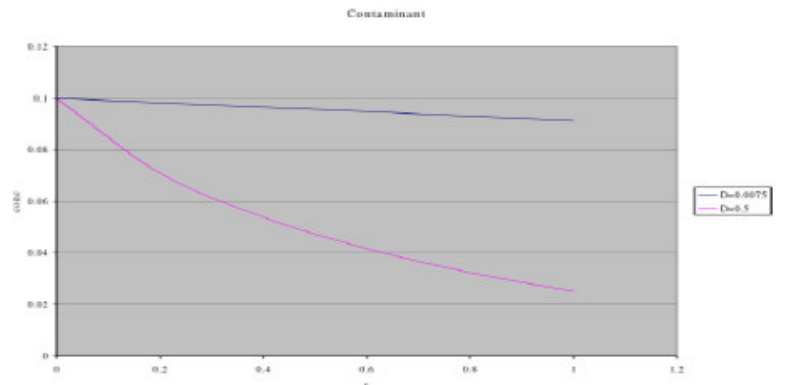

Fig. 3: Varying the value for the diffusive term 'D'

\section{CONCLUSION}

In this paper we have discussed the various models involving water pollutant transport equation. We have also given the implicit central difference scheme in space, and a forward difference method in time for the evaluation of the generalized transport equation. And have given profiles for different parameter values

\section{REFERENCES}

1. Ames, W. F.: 1988, Analysis of Mathematical Models for Pollution Transport and Dissipation, Comput. Math. Applic. 16, 939-985.
2. Andrea Bagnera, Marco Massabò, Riccardo Minciardi, Luca Molini, Michela Robbaa, Roberto Sacile, Optimal Groundwater Exploitation and Pollution Control

3. Bermudez, A., 1993 Mathematical Techniques for Some Environmental Problems Related to Water Pollution Control Mathematicas Climate and Environment, J. I. Diaz and J. L. Lions Eds. Masson, Paris, pp. 12-27.

4. Brebbia, C. A.(Ed): 1976, Mathematical Model for Environmental Problems, Pentech Press, London.

5. Canale R. P. (Ed):1976, Modelling Biochemical Processes in Aquatic Ecosystems, Ann Arbor Science Publ. Inc. Ann Arbor.

6. Carter, C.W., Suffet, I.H.: 1982, Binding of DDT to dissolved humic materials. Environ. Sci. Technol. 16, 735-740.

7. Chiou, C.T., Malcolm, R.L., Brinton, T.I., Kile, D.E.: 1986, Water solubility enhancement of some organic pollutants and pesticides by dissolved humic and fulvic acids. Environ. Sci. Technol. 20, 502-508.

8. Choi, H., Corapcioglu, M.Y.: 1997, Transport of a non-volatile contaminant in unsaturated porous media in the presence of colloids. J. Contam. Hydrol. 25, 299-324.

9. David Krantz and Brad Kifferstein Ahmed : 1991, Water Pollution and Society Longman group U.K. Limited.

10. Gambolati, G., Rinaldo, A., Brebbia, C. A., Gray, W. G., and Pinder, G. F.: 1990. Computational Methods in Surface Hydrology, Springer Verlag, Berlin.

11. Hassett, J.P., Andersion, M.C.: 1979, Association of hydrophobic organic compounds with dissolved organic matter in aquatic system\}. Environ. Sci. Technol. 13, 1526-1529.

12. Jenkins, M.B., Lion, L.W.,: 1993, Mobile bacteria and transport of polynuclear aromatic hydrocarbons in porous media. Appl. Environ. Microbiol. 59, 3306-3313.

13. Kremmer, J. N. and Nixon, S.: 1978, A Coastal Marine Ecosystem, Springer Verlag, New York.

14. Lindqvist, R., Enfield, C.G.: 1992, Biosorption of dichlorodipheny, trichloroethane, and hexachlorobenzene in groundwater and its implications for facilitated transport. Appl. Environ. Microbiol. 58, 2211-2218. 
15. Magee, B.R., Lion, L.W., Lemley, A.T.: 1991, Transport of dissolved organic macromolecules and their effect on the transport of phenanthrene in porous media. Environ. Sci. Technol. 25, 324-331.

16. McCarthy, J.F., Zachara, J.M.: 1989, Subsurface transport of contaminants. Environ. Sci. Technol. 23, 496-502.

17. Nihoul, J. (Ed): 1975, Modelling of Marine Systems, Elsevier, Amsterdam.

18. Rich, L. G.: 1973, Environmental Systems Engineering, Mc Graw Hill, New York.

19. Ryan, J.N., Elimelech, M.: 1996, Colloid mobilization and transport in groundwater. Colloids Surf. A 107, 1-56.

20. Roberts J. Schilling and Sandra L. Harris: 2000, Applied Numerical Methods for Engineers, Using MATLAB and C Brooks/Cole Thomson Learning Pacific Grove.
21. Song-Bae Kim, M. Yavuz Corapcioglu: 2002, Contaminant transport in riverbank filtration in the presence of dissolved organic matter and bacteria: a kinetic approach Journal of Hydrology 266269 283

22. Theim, G.: 1906, Hydrologische Methoden, Gebhardt, Leipzig, pp. 56, (in German)

23. Thomann, R. V.: 1972, Systems Analysis and Water Quality Management, Environmental Research and Applications Inc, New York.

24. The Green Lane ${ }^{\mathrm{TM}}$, Environment Canada's World Wide Web site The Management of Water, http://www.ec.gc.ca 